Pulished in : Cortex (2007), 43, 866-874

Status : Postprint (Author's version)

\title{
Comparison of inhibitory functioning in mild Alzheimer's disease and frontotemporal dementia
}

\author{
F. Collette ${ }^{1,4}$, H. Amieva ${ }^{2}$, S. Adam ${ }^{1}$, M. Hogge ${ }^{1}$, M. Van der Linden ${ }^{1,3}$, \\ C. Fabrigoule ${ }^{2}$, E. Salmon ${ }^{4,5}$
}

${ }^{1}$ Department of Cognitive Sciences, University of Liège, Belgium, ${ }^{2}$ INSERM U593, Bordeaux, France, ${ }^{3}$ Cognitive Psychopathology Unit, University of Geneva, Switzerland, ${ }^{4}$ Cyclotron Research Centre, University of Liège, Belgium, ${ }^{5}$ Memory Centre, Service of Neurology, CHU Liège, Belgium

\begin{abstract}
Executive dysfunction is frequently reported in Alzheimer's disease (AD) and the frontal variant of frontotemporal dementia (FTD). More specifically, inhibitory dysfunction is observed early in AD and inhibitory deficits are also prominent in patients with FTD. However, few studies have simultaneously explored and compared inhibitory abilities in both degenerative diseases. Consequently, the aim of this study was to compare verbal and motor inhibitory processes in the initial stages of AD and the frontal variant of FTD. Stroop and go/no-go tasks were administered. The results demonstrate that, on the go/nogo task, AD and FTD patients do not produce more errors than control subjects. However, both groups are impaired on the Stroop task (mainly with regard to the error score) but do not differ from each other. These results indicate that AD and FTD patients do not present a general impairment of their inhibitory abilities. Moreover, these two kinds of dementia present similar quantitative and qualitative inhibitory impairments on the two tasks, although their patterns of structural and functional cerebral impairments are known to be different. The presence of similar inhibitory deficits despite very different patterns of brain damage is in agreement with the hypothesis that inhibitory dysfunction in the two groups of patients depends on a disconnection process between anterior and posterior cerebral areas, rather than on the presence of focal metabolism decreases in different regions.
\end{abstract}

Address for correspondence:

Fabienne Collette, Neuropsychology Unit,Boulevard du Rectorat 3 (B33), 4000 Liège, Belgium.

Telephone: (32) 43662274

Fax: (32) 43662875

E-mail: f.collette@ulg.ac.be 
Pulished in : Cortex (2007), 43, 866-874

Status : Postprint (Author's version)

\section{Introduction}

Executive dysfunction is frequently reported in neurodegenerative diseases such as Alzheimer's disease (AD; for a review, see Collette \& Van der Linden, 2004) or frontotemporal dementia (FTD; for a review, see Grossman, 2002). Inhibitory control is classically considered as representing an important executive function (e.g., Miyake et al., 2000). Inhibitory impairments have been reported in several neuropsychological conditions, as well as in normal aging (e.g., Hasher \& Zacks, 1988) and numerous psychopathological syndromes (for a review, see Nigg, 2000). Inhibition is generally defined as the set of processes that allow the suppression of previously activated cognitive contents, the clearing of irrelevant actions or of attentional focus from consciousness, and the resistance to interference from potentially attention-capturing stimuli (Bjorklund \& Harnishfeger, 1995). Consequently, different aspects of inhibitory control may be distinguished, including preventing access to goal-irrelevant information that may be partially activated, restricting access to strong but situationally inappropriate responses, and suppressing the activation of no-longer-relevant information. Inhibitory processes have been examined in pathological populations by using different procedures, the most frequently used being the Stroop task (Stroop, 1935), the negative priming procedure (Neill, 1977; Tipper, 1985), the inhibition of return paradigm (Posner \& Cohen, 1984), the go/no-go task (Band \& Van Boxtel, 1999) and the Hayling task (Burgess \& Shallice, 1996).

Inhibitory deficits have frequently been reported in the first stages of Alzheimer's disease (for reviews, see Amieva et al., 2004; Balota \& Faust, 2001; Collette \& Van der Linden, 2002b). Typically, the Stroop interference effect is considerably greater in AD patients than in healthy elderly controls, even after adjustment of interference scores for processing speed (Amieva et al., 2004; Bondi et al., 2002; Fisher et al., 1990; Koss et al., 1984; Spieler et al., 1996). Similarly, a less reliable or absent negative priming effect has been observed in these patients (Amieva et al., 2002; Sullivan et al., 1995; see, however, Langley et al., 1998) and weaker semantic inhibition abilities have also been observed (Collette et al., 1999; Duchek et al., 1998). Nevertheless, not all inhibitory processes appear to be impaired in AD. Little evidence of inhibitory dysfunction has been found in tasks that assess motor response inhibition (Amieva et al., 2002; see, however, Collette et al., 2002c) and inhibition-of-return (Danckert et al., 1998; Faust \& Balota, 1997; Langley et al., 2001).

It is noteworthy that very few studies have attempted to determine how general the inhibitory dysfunction in AD is by administering a battery of inhibitory tasks to a single group of patients. In a first study, Collette et al. (1999) administered a series of 6 executive tasks to a group of $\mathrm{AD}$ patients, and demonstrated that the impaired performance on all these tasks can be grouped into two factors, representing respectively dual task coordination and inhibitory processes. More recently, Belleville et al. (2006) administered two tasks assessing verbal inhibitory processes, the Stroop and the Hayling tasks, to a group of AD patients and elderly subjects, and demonstrated impaired performance on both tasks in the patients. Such results are consistent with the view of a generality of inhibitory dysfunction in AD, at least in the verbal domain. However, if the majority of the patients was impaired on the Hayling task, only $50 \%$ showed deficits on the Stroop task that cannot taken into account, at least in part, by reading or naming difficulties. The existence of a general impairment across domains was reported by Collette et al. (2002c) who did not find evidence of preserved inhibitory functioning in a group of 
Pulished in : Cortex (2007), 43, 866-874

Status : Postprint (Author's version)

AD patients by using the Stroop, Hayling and go/no-go tasks. However, Amieva et al. (2002) obtained data in agreement with the hypothesis of some specificity in the inhibitory dysfunction in $\mathrm{AD}$. Indeed, these authors observed impaired performance on the negative priming and Stroop tasks, but not on the go/no-go task, and only limited impairment was observed on the stop-signal task, suggesting that motor response inhibition may be relatively spared in those patients. Discrepant results on the go/no-go task, in particular, could be attributed to the severity of the disease since the group of $\mathrm{AD}$ patients in the Collette et al. study had a lower score and more variable performance on the MMSE than the patients in the Amieva et al. study. Finally, intact performance on tasks of interference resolution and directed forgetting in working memory was recently found to be associated with impaired performance on two semantic inhibitory tasks (the Hayling and flanker tasks) (Collette et al., submitted). These results also favored specificity rather than generality of inhibitory dysfunction in AD patients.

Behavioural disorders constitute a major clinical characteristic of FTD patients (Gregory \& Hodges, 1996; Gregory et al., 1998). Indeed, these patients present a number of behavioural disturbances such as inflexibility, disinhibition and impulsivity, distractibility and lack of persistence, as well as perseverative behaviour (Gustafson, 1987, 1993), and these behavioural abnormalities are associated with cognitive deficits involving executive functioning in particular. Indeed, studies of cognitive functioning in the frontal variant of FTD have found a significant impairment on executive tasks, associated with variable memory performance, but only moderate deficits affecting language, constructional abilities and IQ (Jagust et al., 1989; Johansen \& Hagberg, 1989; Miller et al., 1991; Neary et al., 1986; Pachana et al.,

1996). However, at this time very few studies have been interested in formally exploring inhibitory dysfunction in these patients. Using a Stroop task, Perry et al. (2000) compared the performance of $\mathrm{AD}$ patients to that of patients with the frontal and temporal variants of FTD. Their results indicated poorer performance for all three groups of patients in comparison to control subjects, but no significant differences among the dementia groups. Similarly, Pachana et al. (1996) demonstrated that control subjects performed at a significantly higher level than both $\mathrm{AD}$ and FTD patients on the time measure of the Stroop task, but no significant difference was detected between patient groups. Mendez et al. (2005), using an alternate tapping task and the go/no-go task, reported significant differences between FTD patients who did and did not show sociopathic behaviour. Semantic inhibition deficits have also been shown in these patients using the Hayling task (Lough et al., 2006). Finally, Dimitrov et al. (2003) compared the inhibitory performance of FTD patients to that of matched control subjects using the stopsignal and negative priming tasks. The results indicated a moderate impairment, in the sense that, on the stop-signal task, the FTD patients were less accurate in their 'go' responses and marginally less able to inhibit their responses on the 'stop' trials. In the negative priming task, FTD patients, unlike control subjects, did not show the negative priming effect. However, this result must be interpreted with caution since no interaction between group and task condition was found. Moreover, directly comparing the patients' performance on the two inhibitory tasks was difficult since the two tasks were not performed by exactly the same patients, and no indication was provided of why some patients withdrew or whether the testing occurred at the same time for the two tasks.

Overall, the results of these studies indicate that inhibitory dysfunction is frequently found in $\mathrm{AD}$ and FTD patients. However, at this time, no study has formally compared the inhibitory capacities of these patients using tasks that assess various inhibitory processes. Consequently, the aim of the present study was to give AD patients, patients with the frontal variant of FTD and matched control subjects two tasks assessing inhibitory processes that are considered to be 
Pulished in : Cortex (2007), 43, 866-874

Status : Postprint (Author's version)

separate in the literature (for example, Harnishfeger, 1995; Nigg, 2000): the Stroop task, which involves the inhibition of compelling verbal responses, and the go/no-go task, which involves the inhibition of compelling motor responses. These tasks were selected because they measure the ability to inhibit a dominant response but involve two different (verbal and motor) response modalities. Moreover, functional neuroimaging studies in healthy subjects demonstrated that the Stroop and the Go-No tasks were not associated to similar cerebral network (Collette \& Van der Linden, 2002a). In a previous study, Amieva et al. (2002) demonstrated an impaired performance on the Stroop task only in AD patients. We were interested to replicate these last results in AD, and to determine whether they could be extended to FTD.

Comparison of the performance of each patient group to that of healthy control subjects will make it possible to determine the generality or specificity of inhibitory dysfunction in each pathology. Moreover, a comparison of the two groups of patients will allow us to determine whether the pattern of deficit is similar, at both quantitative and qualitative levels. This is a key question, since these two neurodegenerative diseases are associated with specific patterns of cerebral hypometabolism in functional imaging studies (Frisoni et al., 1996; Salmon et al., 1994, 2003; Sjogren et al., 2000).

\section{Methods}

\section{Subjects}

Sixty-six community-dwelling adults volunteered to participate in this study. All subjects had normal or corrected vision and normal or corrected hearing. The 28 normal elderly subjects (13 men and 15 women) had an average age of $70.6 \pm 6.8$ years (range $=53-82$ ). These subjects were alert, and had no history of neurological problems, alcohol abuse or psychiatric disorders. All elderly participants were native speakers of French and did not report any medical, neurological or sensory defects, or use of medication likely to alter cognitive functioning.

A total of 38 patients attending the Day Care Centre for Memory Disorders in the Elderly (University Hospital of Liège) also participated in this study. Clinical diagnoses were made according to consensual criteria for probable AD (McKhann et al., 1984) and FTD (Neary et al., 1998) based on (1) the demographic information and clinical history obtained during an interview with the patient and a caregiver, and (2) neurological and general examinations. To perform the diagnosis, the neurologists had access to recent anatomical neuroimaging and laboratory data, as well as a complete assessment of cognitive functioning performed by a neuropsychologist. Twenty-five patients ( 8 men and 17 women) met the NINCDS-ADRDA criteria for probable Alzheimer's disease (MacKhann et al., 1984). All patients had suffered from progressive worsening of memory problems for at least 6 months. Structural neuroimaging showed only slight atrophy or mild leukoaraiosis. The patients' ages ranged from 55 to 79 years (mean age: $72.5 \pm 5.8$ years). Thirteen patients (5 men and 8 women) were selected according to recent consensual diagnostic criteria for frontotemporal dementia (Neary et al., 1998). The FTD patients showed the behavioural presentation of the disease (the frontal variant or fvFTD); cases with specific characteristics of semantic dementia and primary progressive aphasia were excluded from this study. These patients’ ages ranged from 54 to 76 years (mean age: $65.7 \pm 7.5$ years). Neither AD nor FTD patients suffered from any other medical or neurological condition and they did not take medication that would significantly affect their cognitive performance. They were able to hear and see adequately and follow instructions. 
Pulished in : Cortex (2007), 43, 866-874

Status : Postprint (Author's version)

The normal elderly participants and the two groups of patients were given the Mattis Dementia Rating Scale (Mattis, 1973), which is widely used to screen for global cognitive impairments. All control subjects had a total score of more than 130 on this scale (mean: $139.1 \pm$ 3.3), which constitutes a cut-off score to discriminate normal aging from dementia (Monsch et al., 1995). The control subjects did not differ from AD and FTD patients according to age [respectively, $\mathrm{U}=277.5 ; \mathrm{Z}=1.29, \mathrm{p}>.1$; and $\mathrm{U}=125.5 ; \mathrm{Z}=-1.59, \mathrm{p}>.1$ ] and education level [respectively, $U=284, Z=-1.18, p>.1$; and $U=166.5, Z=0.47, p>.1$ ]. Overall performance on the Mattis Dementia Rating Scale was significantly lower for AD patients $(121 \pm 9.16)$ than for control subjects [U = 7.5; $\mathrm{Z}=-6.11, \mathrm{p}<.0001]$ and also for FTD patients $(127.3 \pm 9.1)$ than for control subjects $[\mathrm{U}=20 ; \mathrm{Z}=-4.55 ; \mathrm{p}<.0001]$. Finally, AD and FTD patients differed regarding age $[U=75.5, Z=-2.68 ; p<.01]$ but not education level $[U=120, Z=1.42 ; p>.1]$ or performance on the Mattis Dementia Rating Scale $[U=99, Z=1.96, p>.05]$.

The study was approved by the Ethic Committee of the University Hospital in Liège and informed consent was obtained in all patients and control subjects.

\section{Procedure}

The participants were tested individually during a two-hour session in a quiet room. Before each task, the subject was given instructions, and a pre-test was performed to ensure that the instructions were understood. Both inhibitory tasks were presented on a microcomputer equipped with a touch screen. Two PVC hand rests, each containing two lateral photoelectric cells, were connected to the computer and placed in front of it. During the test session, subjects were asked to keep their hands on the PVC hand rests at all times before giving their motor response and to put them back on the hand rests after doing so. This equipment made it possible to separately collect in the go/no-go task the subjects' latency in lifting their hands from the start position after the stimulus onset and the time spent reaching the target on the screen. Naming latencies on the Stroop task involving a vocal response were collected with a microphone that was connected to the computer.

\section{Tasks}

Stroop test

The subjects were presented with colour names (BLUE, RED, YELLOW, GREEN) printed in a contrasting ink colour (e.g., BLUE printed in red). In the interference task, the instruction was to name the ink colour and to ignore the meaning of the word. The task comprised 48 trials. After each response by the subject, the experimenter pressed one of three keys to code the response as correct, incorrect or invalid. The code response given by the experimenter initiated the next trial. Each participant began with a practice block of 12 trials. A control task was also administered consisting of 48 trials in which a colour patch, either red, yellow, green or blue, appeared in the centre of the screen. The subject was told to name the colour of the patch presented.

\section{Go/no-go task}

First, subjects were asked to perform a simple reaction time task in which they had to touch, as rapidly as possible, a red circle appearing in the centre of the screen for 20 trials. The go/no-go task was then performed. The task comprised 20 trials in which subjects were presented with either the red circle or a blue triangle in a pseudo-random order. Subjects were told to respond to the red circle by touching it on the screen as quickly as possible, and not to respond to the blue triangle at all. Fifty percent of the trials were 'Go' trials and the other $50 \%$ were 'No-go' trials. In the 'No-go' trials in which the distracter stimulus appeared, two different types of errors were 
Pulished in : Cortex (2007), 43, 866-874

Status : Postprint (Author's version)

possible: subjects could wrongly remove their hand from the starting point, constituting the first error type; then they could replace their hand or continue the action by touching the distracter stimulus on the screen, constituting the second error type.

\section{Statistical analyses}

As most of the data were not normally distributed, the nonparametric Wilcoxon test was used throughout to analyse intergroup and within-group differences. Thus, the statistical tests were done on the mean rank of scores and the mean rank of times of subjects. However, the mean scores and the mean times are also reported as an indicator of data trends. The nonparametric Spearman test was used to do correlation analyses. Statistical analyses were done using STATISTICA software (StatSoft France, 2001). To take into account the age difference between $\mathrm{AD}$ and FTD patients, ANCOVA were also performed with age as a confounding variable. Since results are similar to those obtained with nonparametric tests, these results will not be reported.

\section{Results}

\section{Stroop test}

Subjects' mean latencies to name the ink colour of the stimuli and mean number of errors of are shown in Table 1. Only reaction times for correct trials were analysed.

Table 1. Performance of normal elderly subjects, AD patients and FTD patients on the Stroop test.

\begin{tabular}{l|c|c|c}
\hline & $\begin{array}{c}\text { Normal controls } \\
(\mathbf{n}=\mathbf{2 8}) \\
\text { M (SD) }\end{array}$ & $\begin{array}{c}\text { AD patients } \\
(\mathbf{n}=\mathbf{2 5}) \\
\mathbf{M}(\mathrm{SD})\end{array}$ & $\begin{array}{c}\text { FTD patients } \\
(\mathbf{n}=\mathbf{1 3}) \\
\text { M(SD) }\end{array}$ \\
\hline Colour naming task & $719(150)$ & $934(305)$ & $933(181)$ \\
\hline Naming latency (ms) & $0.14(0.36)$ & $0.60(1.19)$ & $0.50(0.90)$ \\
Errors & $985(184)$ & $1425(524)$ & $1424(281)$ \\
Stroop task & $0.96(1.14)$ & $4.88(6.37)$ & $3.77(3.22)$ \\
Naming latency (ms) & $1.38(0.16)$ & $1.54(0.35)$ & $1.57(0.44)$ \\
Interference ratio ${ }^{1}$ & $266(110)$ & $491(318)$ & $491(384)$ \\
Interference 'differential score'2
\end{tabular}

${ }^{1}$ Naming latency on Stroop $\div$ naming latency on colour naming

${ }^{2}$ Naming latency on Stroop - naming latency on colour naming

The comparison of the performance of AD patients and normal elderly subjects on the colour naming task demonstrated significantly increased naming latency for AD patients $[\mathrm{U}=$ $188, \mathrm{Z}=2.29 ; \mathrm{p}<.005]$ but a similar error rate in the two groups $[\mathrm{U}=282, \mathrm{Z}=1.66, \mathrm{p}>.9]$. On the Stroop task, both the naming latencies and error rates were significantly higher for AD patients than for normal elderly subjects [respectively, $U=159, Z=3.40, p<.001$; and $U=150$, $\mathrm{Z}=3.55, \mathrm{p}<.001$ ]. The interference ratio (naming latency on the Stroop task $\div$ naming latency on the colour naming task) was marginally different for the groups $[U=247, Z=1.83, p<.066]$. 
Pulished in : Cortex (2007), 43, 866-874

Status : Postprint (Author's version)

Their performance, however, became significantly different when a subtraction score (interference - naming) was used [ $\mathrm{U}=206, \mathrm{Z}=2.57, \mathrm{p}<.05]$.

The comparison of the performance of FTD patients and normal elderly subjects on the colour naming task demonstrated a significant difference between the groups for naming latency $[U=53, Z=3.39, p<.001]$ but not for error rates $[U=134, Z=1.44, p<.1]$. On the Stroop task, both the naming latencies and the error rates were significantly higher for FTD patients than for elderly subjects [respectively, $U=27, Z=4.16, p<.001$; and $U=78, Z=2.91, p<.005$ ]. The interference ratio (naming latency on the Stroop task $\div$ naming latency on the colour naming task) was not statistically different for the groups $[\mathrm{U}=146, \mathrm{Z}=0.13, \mathrm{p}>.5]$. Again, this difference became significant when assessed with a subtraction score (interference - naming) [U $=81, \mathrm{Z}=2.57, \mathrm{p}<.05]$.

Finally, the comparison of the performance of AD and FTD patients failed to find any significant differences for the colour naming task [naming latency: $U=137, Z=0.42, p>.5$; naming errors: $U=150, Z=0, p>.5]$. Similarly, no significant differences were found on the Stroop task [naming latency: $U=133, Z=0.55, p>.5$; naming errors: $U=157, Z=0, p>.5$ ]. Finally, the interference ratio (naming latency on the Stroop task $\div$ naming latency on the colour naming task) was also similar between groups $[\mathrm{U}=147, \mathrm{Z}=0.62, \mathrm{p}>.5]$, as was the subtraction ratio (interference - naming) $[\mathrm{U}=145, \mathrm{Z}=-0.16, \mathrm{p}>$.5].

\section{Go/no-go task}

Simple reaction time condition

The mean simple reaction times and error rates of the normal controls and the two groups of patients are shown in Table 2. Comparison of the performance of AD patients and normal elderly subjects revealed significantly longer response latencies and reaching times in AD patients [respectively, $U=176, Z=3.10, p<.005$; and $U=75, Z=4.90, p<.0001$ ]. Similar analyses were performed with the group of FTD patients and again found significantly longer response latencies and reaching times [respectively, $U=73, \mathrm{Z}=3.05, \mathrm{p}<.005$; and $\mathrm{U}=62, \mathrm{Z}=3.05, \mathrm{p}<$ .001]. However, the comparison of AD and FTD patients demonstrated no significant differences for these measures [response latencies: $U=149, Z=0.41, p>.5$; reaching times: $U=112, Z=-$ $1.55, \mathrm{p}>.5]$.

Go/no-go condition

The subjects' mean reaction times and error rates on the go/no-go task are also shown in Table 2 . Only analyses for "leaving hand" errors were reported since no control subject or patient produced a touching error. Both responses latencies and reaching times were significantly longer for $\mathrm{AD}$ patients than for elderly subjects [respectively, $\mathrm{U}=174, \mathrm{Z}=3.14, \mathrm{p}<.005$; and $\mathrm{U}=80, \mathrm{Z}$ $=4.18, \mathrm{p}<.0001]$. Time ratios were calculated between the simple reaction time task and the go/no-go task in order to assess the cognitive slowing during 'go' trials attributable to the presence of 'no-go' trials, and to reduce the influence of patients' cognitive slowing on group differences. As can be seen, these mean ratios were not significantly different for the groups, either for the response latencies or for the reaching times

[respectively, $\mathrm{U}=287, \mathrm{Z}=1.12, \mathrm{p}>.1$; and $\mathrm{U}=349, \mathrm{Z}=-0.01, \mathrm{p}>$.5]. Similarly, no significant difference appeared when a subtraction score (go/no-go - simple reaction time) was used [respectively, $\mathrm{U}=343, \mathrm{Z}=0.12, \mathrm{p}>.5$; and $\mathrm{U}=343, \mathrm{Z}=0.12, \mathrm{p}>.5$ ]. In the 'no-go' trials, errors consisting in removing the hand from the starting point after the appearance of the distracter stimulus on the screen were not significantly different between the $\mathrm{AD}$ patients and the elderly controls [ $=327, \mathrm{Z}=0.42, \mathrm{p}>$.5]. 
Pulished in : Cortex (2007), 43, 866-874

Status : Postprint (Author's version)

The comparison of FTD patients and normal elderly subjects also demonstrated significantly longer response latencies and reaching times for FTD patients [respectively, $U=58$, $\mathrm{Z}=3.47, \mathrm{p}<.001$; and $\mathrm{U}=67, \mathrm{Z}=3.22, \mathrm{p}<.05]$. However, these differences disappeared when time ratios were used [response latencies: $U=127, Z=1.54, p>.1$; reaching times: $U=181, Z=$ 0.03, $\mathrm{p}>$.5]. Similarly, no significant difference appeared when a subtraction score (go/no-go simple reaction time) was used (respectively, $U=174, Z=0.22, p>.5 ; U=174, Z=-0.22$, $p>$ $.5]$. The number of errors in the 'No-go' trials was also similar for the two groups $[U=160, Z=$ $0.62, \mathrm{p}>.5]$.

Finally, the comparison of the two groups of patients demonstrated similar performance in terms of both response latencies $[\mathrm{U}=132, \mathrm{Z}=0.93, \mathrm{p}>.1]$ and reaching times $[\mathrm{U}=113, \mathrm{Z}=-$ 1.52, $\mathrm{p}>.1$ ], as well as for time ratios [response latencies: $U=153, Z=0.29, p>.5$; reaching times: $\mathrm{U}=159, \mathrm{Z}=-0.11, \mathrm{p}>.5$ ], difference between simple reaction time and go/no-go [response latencies: $U=159, Z=-0.11, p>.5$; reaching times: $U=154, Z=-0.26, p>.5$ ] and errors in the 'no-go' trials [ $\mathrm{U}=155, \mathrm{Z}=0.22, \mathrm{p}>.5]$.

Table 2. Mean reaction times of normal elderly subjects, AD patients and FTD patients on the simple reaction time and the go/no-go tasks.

\begin{tabular}{|c|c|c|c|}
\hline & $\begin{array}{c}\text { Normal controls } \\
(\mathbf{n}=\mathbf{2 8}) \\
\mathbf{M}(\mathrm{SD})\end{array}$ & $\begin{array}{l}\text { AD patients } \\
\text { (n = 25) } \\
\mathbf{M}(\mathrm{SD})\end{array}$ & $\begin{array}{l}\text { FTD patients } \\
\text { (n = 13) } \\
\text { M(SD) }\end{array}$ \\
\hline \multicolumn{4}{|c|}{ Simple reaction time (without any 'no-go' trial) } \\
\hline Mean response latency (ms) & $356(96)$ & $505(245)$ & $527(161)$ \\
\hline Mean reaching time (ms) & $514(115)$ & $842(266)$ & $726(227)$ \\
\hline \multicolumn{4}{|l|}{ Go/no-go task } \\
\hline Response latency (ms) ${ }^{1}$ & $468(85)$ & $602(177)$ & $636(182)$ \\
\hline Reaching time (ms) ${ }^{1}$ & $513(106)$ & $805(266)$ & $722(236)$ \\
\hline Hand movement errors & $2.21(1.29)$ & $2.56(1,85)$ & $2.85(2.34)$ \\
\hline Touching errors & 0 & 0 & 0 \\
\hline \multicolumn{4}{|l|}{ Time ratios } \\
\hline Response latency ratio $^{1}$ & $0.76(0.12)$ & $0.83(0.25)$ & $0.84(0.17)$ \\
\hline Reaching time ratio ${ }^{1}$ & $1.01(0.19)$ & $1.21(1.04)$ & $1.01(0.15)$ \\
\hline Response latency difference ${ }^{2}$ & $-112(66)$ & $-96(160)$ & $-109(124)$ \\
\hline Reaching time difference $^{2}$ & $1.4(102)$ & $37(278)$ & $4(118)$ \\
\hline
\end{tabular}

${ }^{1}$ Simple reaction time task $\div$ go/No-go task

${ }^{2}$ Simple reaction time task - go/No-go task

\section{Correlation analyses}

Correlation analyses were performed separately for the two patient groups between the two interference ratios on the Stroop task and the two ratios for response latencies on the go/no-go task. These measures were also correlated to the overall level of dementia as assessed by the Mattis DRS. The only significant correlation was found between the subtraction time ratio scores on the Stroop and go/no-go tasks in the FTD patients $[r(12)=0.68, \mathrm{p}<.05]$. 
Pulished in : Cortex (2007), 43, 866-874

Status : Postprint (Author's version)

\section{Discussion}

The main goal of this study was to determine the generality of inhibitory dysfunction in two neurodegenerative conditions, AD and FTD, by using tasks assessing motor and verbal inhibitory processes. Moreover, we were interested in directly comparing the patterns of performance presented by these patients at a mild stage of the disease.

The results obtained can be summarised as follows. On the Stroop task, both AD and FTD patients demonstrate a slowing down (as evidenced by response latencies) in the naming and interference conditions. Moreover, specific inhibitory difficulties affecting this task are observed in both populations. Indeed, in comparison to normal elderly subjects, AD and FTD patients produced more errors in the interference condition and a higher interference ratio (as assessed by a subtraction score). However, these inhibitory difficulties are similar in both groups of patients. With regard to the go/no-go test, the simple reaction time condition resulted in longer response latencies and reaching times in the two groups of patients in comparison with normal elderly subjects, but no differences between the two groups of patients. In the go/no-go condition, longer response latencies and reaching times were observed in the two groups of patients compared to normal elderly subjects, but these differences disappeared when a ratio score was considered. No differences between patients and control subjects were observed for the errors on the 'no-go' trials. Finally, as was previously observed for the Stroop task, no significant differences between AD and FTD patients were observed on these measures (Pachana et al., 1996; Perry et al., 2000).

Previous studies that explored inhibitory functioning in FTD and AD patients also found consistent impairment on the Stroop task (e.g., Amieva et al., 2004; Pachana et al., 1996; Perry et al., 2000; Spieler et al., 1996), and, as observed in the present study, that impairment was similar in scope in both groups of patients (Pachana et al., 1996; Perry et al., 2000). With regard to motor inhibition, results of previous studies are less consistent, with different studies indicating impaired (Collette et al., 2002c) or normal (Amieva et al., 2002) performance in AD, whereas impaired performance was also reported in FTD (Dimitrov et al., 2003). However, most of these studies did not control for the influence of a general slowing down on inhibitory performance. On the other hand, we determined inhibitory functioning with ratio scores that take these aspects of processing speed into account, which suggests that the inhibitory dysfunction observed in these populations cannot be related to an impairment of a general speed factor, as has sometimes been proposed for normal aging (Verhaegen \& De Meersman, 1998).

Taken as a whole, the results obtained in this study indicate that neither AD nor FTD patients present a widespread inhibitory dysfunction. Indeed, although both groups of patients are impaired on the Stroop task (both for response times and, most obviously, for error scores), they do not make more errors on the 'no-go' trials of the go/no-go condition. Moreover, only one significant correlation was observed between inhibitory measures on the two tasks. The result of poor correlations between tasks supposed to reflect a same inhibitory (or more generally executive) process was already reported in the literature (see for example, Shilling et al., 2002). If these results can be interpreted as reflecting a weak validity of the construct of inhibition (Rabbit et al., 2001), we can also consider that it constitutes a supplementary argument to consider that the Stroop and Go/No-go tasks really tap two distinct inhibitory processes, that are differentially affected in AD and FTD. This pattern of results is in agreement with the theoretical proposals of a growing number of authors who consider that inhibitory functioning actually refers to a series of independent processes (e.g., Bjorklund \& Harnishfeger, 1995; Dempster \& Corkill, 1999a, b 
Pulished in : Cortex (2007), 43, 866-874

Status : Postprint (Author's version)

Nigg, 2000). In that context, Houghton and Tipper's (1994) proposal appears particularly interesting. These authors considered the cognitive operations on which inhibitory mechanisms are exerted and stated that 'the strength of the inhibition continually adapts to the strength of the to-be-ignored inputs' (p. 107). In other words, the strength of the cognitive operation/content that has to be suppressed will determine the degree of effortfulness of the mechanisms required to inhibit it. This characteristic of inhibitory functioning may be relevant in explaining why performance on the go/no-go task is preserved in AD and FTD. Indeed, in our study, 50\% of trials were 'go' trials and 50\% were 'no-go' trials (this is a classical proportion for this kind of task, cf. Zimmerman, 1994). This would have resulted in relatively weak reinforcement of the motor response to 'go' trials. On the other hand, most of the tasks impaired in AD patients share the characteristic that the process to be suppressed is salient or mandatory, as in the Stroop test, which calls for the inhibition of the reading of familiar names, known to be an over-learned mandatory process, or the Hayling task, which requires the suppression of a mandatory word that springs to mind. In that case, the inhibitory processing required is necessarily effortful and controlled, which explains the difficulties AD and FTD patients have in performing this kind of task.

It must be emphasised that FTD and AD patients present similarly impaired performance on the Stroop task (for both response times and accuracy of responses). Very few studies have compared the inhibitory abilities of AD and FTD patients, but those that did also demonstrated a similar impairment in the two groups of patients (Pachana et al., 1996; Perry et al., 2000). These data appear rather surprising since each pathology is associated with specific morphological and metabolic impairments. Indeed, functional neuroimaging studies indicate that patients with FTD present hypometabolism or hypoperfusion predominantly in the medial frontal area as well as in the temporal pole, while AD is associated with decreased cerebral blood flow or hypometabolism preferentially observed in the parieto-temporo-occipital associative cortex (Frisoni et al., 1996; Salmon et al., 1994, 2003; Sjogren et al., 2000). In that context, two explanations can be tentatively proposed to explain the similar impairments of our two groups of patients. First, it could be argued that performance on the Stroop task is impaired in the same way in our two populations for different cognitive reasons. However, both similar inhibitory performance (for both response times and accuracy of responses) and similar processing speed were observed in our two groups. Moreover, processing speed did not influence inhibitory dysfunction in either group. Taken as a whole,

these findings do not support the hypothesis that different cognitive processes may explain the similar deficit observed in the AD and FTD patients.

From a neuroimaging viewpoint, an alternative hypothesis would be that impairment on the Stroop task in AD and FTD is not due to hypometabolism in the specific brain areas altered by each of these two neurodegenerative disorders but rather to a more general disconnection process affecting several cerebral areas. Performance on the Stroop task is associated with a large network that is widely distributed throughout the cortex. This network involves the anterior cingulate gyrus, right orbitofrontal regions (Bench et al., 1993; Larrue et al., 1994; Pardo et al., 1990), but also the left inferior frontal regions (Bush et al., 1998; George et al., 1994; Taylor et al., 1997), as well as temporal and parietal areas (Bush et al., 1998; Taylor et al., 1997). A disconnection process would lead to a less efficient transfer of information between the various cerebral areas involved in the Stroop task. In agreement with this hypothesis, many data lead one to consider $\mathrm{AD}$ as a disconnection syndrome (e.g., Collette et al., 2002c; for reviews, see Delbeuck et al., 2003; Morris, 1994). Although the hypothesis that there is a disconnection syndrome in FTD has not yet been formally tested, different clusters of metabolic covariance 
Pulished in : Cortex (2007), 43, 866-874

Status : Postprint (Author's version)

have recently been highlighted in this disease, and a functional disconnection between those clusters is likely to subserve certain clinical symptoms in the disease (Salmon et al., 2006). In that context, the similar inhibitory impairment on the Stroop task in the two groups of patients could be related to a less efficient transfer of information within the network of areas involved in the Stroop task, rather than to a specific impairment of cerebral areas known to be hypometabolic from the first stages of AD and FTD.

As indicated previously, behavioural disinhibition and impulsivity (referring to the production of socially inappropriate comments and/or actions) are prime characteristics of FTD (Cummings, 1993; Starkstein, 1997). However, this behavioural disinhibition was not accompanied in the present study by more severe cognitive inhibitory deficits in comparison to $\mathrm{AD}$ patients. These data suggest that social/behavioural inhibition may be relatively independent of cognitive inhibition. However, further studies will be necessary to determine the pattern of relationships between these two kinds of inhibitory processes in FTD.

Finally, it has recently been stated that inhibitory measures might constitute an efficient way of differentiating between AD and FTD (Slachevsky et al., 2004; Dubois et al, 2000). However, our results indicate that none of the inhibitory measures investigated in this study can be used to discriminate between these two patient groups, and further studies will be necessary to evaluate the discriminatory power (i.e., the sensitivity and sensibility) of various inhibitory scores in the differential diagnosis of AD and FTD. It can be suggested that inhibitory tasks more related to social situations would be better adapted to discriminating between these populations than inhibitory tasks that explore very specific cognitive processes.

In conclusion, the data obtained in the present study indicate that patients with AD and the frontal variant of FTD do not present a general decline in inhibitory functioning. Moreover, these two groups of patients present a similar impairment on the Stroop task, which may be related to the presence of a (partial) disconnection within the network of cerebral areas recruited during performance on the Stroop task. The existence of a specificity in the inhibitory dysfunction occurring in these two neurodegenerative diseases should nevertheless be replicated in a large scale study using a wide range of tasks, build up to specifically assess different inhibitory processes. Indeed, our results concern only the inhibition of a dominant response in the verbal and motor domains, and other theoretical frameworks were proposed in the literature distinguishing between more specific inhibitory processes (e.g. Friedman \& Miyake, 2004; Nigg, 2000). Ideally, each process should be assessed by several experimental tasks to increase the sensitivity and validity of the inhibitory measures (Rabbit et al., 2001).

\section{ACKNOWLEDGEMENTS}

This work was supported by the Belgian National Fund for Scientific Research (FNRS), the Interuniversity Attraction Poles Program P5/04, Belgian Science Policy and a conjoint fund of the CGRI/INSERM (1998/0902/av-n²93.03). F. Collette and M. Hogge are a Research Associate and a Doctoral Researcher at the FNRS, respectively.

\section{REFERENCES}

Amieva H, Lafont S, Auriacombe S, LeCarret N, Dartigues J-F, Orgogozo J, and FABRIGOULE C. Inhibitory breakdown and dementia of the alzheimer type: A general phenomenon? Journal of Clinical and Experimental Neuropsychology, 24: 503-516, 2002. 
Pulished in : Cortex (2007), 43, 866-874

Status : Postprint (Author's version)

Amieva H, Phillips L.H, Della Sala S, and HenRy JD. Inhibitory functioning in alzheimer's disease: A review. Brain, 127: 949-964, 2004.

BALOTA DA, and FAUST ME. Attention in dementia of the alzheimer's type. In Boller F and Cappa SF (Eds.), Handbook of neuropsychology. Amsterdam: Elsevier, 2001, pp. 51-80.

BAND GPH., and VAN BOXTEL GMJ. Inhibitory motor control in stop paradigms: Review and reinterpretation of neural mechanisms. Acta Psychologica, 101: 179-211, 1999.

Belleville S, Rouleau N, and VAN DER Linden M. Use of the Hayling task to measure inhibition of prepotent responses in normal aging and Alzheimer's disease. Brain and Cognition, 62: 113-119, 2006.

Bench CJ, Frith CD, Grasby PM, Friston KJ, Paulesu E, Frackowiak RSJ, and Dolan RJ. Investigations of the functional anatomy of attention using the stroop test. Neuropsychologia, 31: 907-922, 1993.

BJORKLUND DF and HARNISHFEGER K K. The evolution of inhibition mechanisms and their role in human cognition and behavior. In Dempster F.N. and Brainerd C.J. (Eds.), Interference and inhibition in cognition. San Diego: Academic Press, 1995, pp. 142-173.

Bondi MW, Serody AB, Chan AS, Eberson-Shumate SC, Delis DC, Hansen LA, and SALMON DP. Cognitive and neuropathologic correlates of stroop color-word test performance in alzheimer's disease. Neuropsychology, 16: 335-343, 2002.

BuRgess PW, and SHALLICE T. Response suppression, initiation and strategy use following frontal lobe lesions. Neuropsychologia, 34: 263-273, 1996.

Bush G, Whalen PJ, Rosen BR, Jenike MA, McInerney SC, and Rauch SL. The counting stroop: An interference task specialized for functional neuroimaging. Validation study with functional mri. Human Brain Mapping, 6: 270-282, 1998.

COLLETTE F and VAN DER LINDEN M. Brain imaging of the central executive component of working memory [Review]. Neuroscience and Biobehavioral Review, 26: 105-125, 2002a.

COlletTe $\mathrm{F}$ and VAN DeR Linden M. Attention disorders in degenerative syndromes. In Leclercq M and Zimmerman P (Eds), Applied neuropsychology of attention: Theory, diagnosis and rehabilitation. London: Psychology Press, 2002b, pp. 305-338.

COlLETTE F and VAN DeR Linden M. Executive functions in alzheimer's disease. In Morris RG and Becker JT (Eds), Cognitive neuropsychology of alzheimer's disease. Oxford: Oxford University press, 2004, pp. 103-120.

Collette F, VAN Der Linden M and SAlmon E. Executive dysfunction in alzheimer's disease. Cortex, 35: 57-72, 1999.

Collette F, Van Der Linden M, Delrue G and Salmon E. Frontal hypometabolism does not explain inhibitory dysfunction in alzheimer's disease. Alzheimer Disease and Associated Disorders, 16: 228-238, 2002c.

CUMMINGS JL. Frontal-subcortical circuits and human behavior. Archives of Neurology, 50: 873-880, 1993.

DANCKERT J, MARUfF P, CROWE S and CURRIE J. Inhibitory processes in covert orienting in patients with alzheimer's disease. Neuropsychology, 12: 225-241, 1998.

DelbeucK X, VAn Der Linden M and Collette F. Alzheimer's disease as a dysconnection syndrome. Neuropsychology Review, 13 : 79-92, 2003.

DEMPSTER FN and CORKILL AJ. Individual differences in susceptibility to interference and general cognitive ability. Acta Psychologica, 101: 395-416, $1999 \mathrm{~b}$.

DEMPSTER FN and CORKILL AJ. Interference and inhibition in cognition and bahavior: Unifying themes for educational psychology. Educational Psychology Review, 11: 1-88, 1999a. 
Pulished in : Cortex (2007), 43, 866-874

Status : Postprint (Author's version)

Dimitrov M, Nakic M, Elpern-Waxman J, Granetz J, O'Grady J, Phipps M, Milne E, LOGAN GD, HASHER L and GRAFMAN J. Inhibitory attentional control in patients with frontal lobe damage. Brain and Cognition, 52: 258-270, 2003.

Dubois B, Slachevsky A, Litvan I and Pillon B.. The FAB. A frontal assessment battery at bedside. Neurology, 55: 1621-1626, 2000.

DUCHEK J, BALOTA DA and THESSING VC. Inhibition of visual and conceptual information during reading in healthly aging and alzheimer's disease. Aging, Neuropsychology and Cognition, 5: 169-181, 1998.

FAUST ME and BALOTA DA. Inhibition of return and visuospatial attention in healthy older adults and individuals with dementia of the alzheimer type. Neuropsychology, 11: 13-29, 1997.

FISHER LM, FREED DM and CORKIN S. Stroop color-word test performance in patients with alzheimer's disease. Journal of Clinical and Experimental Neuropsychology, 12: 745-758, 1990.

FRIEDMAN NP and MIYAKE, A. The relations among inhibition and interference control functions: A latent variable analysis. Journal of Experimental Psychology: Genera,l 133: 105135, 2004

Frisoni GB, Beltramello A, Weiss C, Geroldi C, Bianchetti A and Trabucchi M. Usefulness of simple measures of temporal lobe atrophy in probable alzheimer's disease. Dementia, 7: 15-22, 1996.

George MS, Ketter ta, Parekh PI, Rosinsky N, Ring H, Casey BJ, Trimble MR, HORWITZ B, HERSCOVITCH P and POST RM. Regional brain activity when selecting a response despite interference: An H2O15 pet study of the stroop and emotional stroop. Human Brain Mapping, 1: 194-209, 1994.

GREGORY CA AND HoDges JR. Frontotemporal dementia: Use of consensus criteria and prevalence of psychiatric features. Neuropsychiatry, Neuropsychology and Behavioral Neurology, 9: 145-153, 1996.

Gregory CA, McKenna PJM and Hodges JR. Dementia of frontal lobe type and simple schizophrenia: Two sides of the same coin? Neurocase, 4: 1-6, 1998.

Grossman M. Frontotemporal dementia: A review. Journal of the International Neuropsychological Society, 8: 566-583, 2002.

GUSTAFSON L. Clinical picture of frontal lobe dementia of non-alzheimer type. Dementia, 4: 143-148, 1993.

GUSTAFSON L. Frontal lobe degeneration of the non-alzheimer type. Ii. Clinical picture and differiential diagnosis. Archives of Gerontology and Geriatrics, 6: 209-223, 1987.

HARNISHFEgER K. The development of cognitive inhibition. Theories, definitions, and research evidence. In Dempster FN and Brainerd CJ (Eds), Interference and inhibition in cognition. London: Academic Press, 1995, pp. 176-206.

HASHER L and ZACKS RT. Working memory, comprehension, and aging: A review and a new view. In Bower GH (Ed.) The psychology of learning and motivation (vol.2). San Diego, CA: Academic Press, 1988, pp. 193-225.

HoughtON G and TIPPER SP. A model of inhibitory mechanisms in selective attention. In Dagenbach D and Carr TH (Eds), Inhibitory processes in attention, memory, and language. San Diego: Academic Press, 1994, pp. 53-112.

Jagust WL, Reed BR, Seab JP, Kramer JH and Budinger TF. Clinical-physiologic correlates of alzheimer's disease and frontal lobe dementia. American Journal of Physiologic Imaging, 4: 89-96, 1989.

JoHANSON A AND HAGBerg B. Psychometric characteristics in patients with frontal lobe degeneration of non-alzheimer type. Archives of Gerontology and Geriatrics, 8: 129-137, 1989. 
Pulished in : Cortex (2007), 43, 866-874

Status : Postprint (Author's version)

Koss E, OBer BA, Delis DC and Friedland RP. The stroop color-word test: Indicator of dementia severity. International Journal of Neuroscience, 24: 53-61, 1984.

LANGLEY LK, FueNTES LJ, HOCHHALTER AK, BRANDT J and OVERMiER JB. Inhibition of return in aging and alzheimer's disease: Performance as a function of task demands and stimulus timing. Journal of Clinical and Experimental Neuropsychology, 23: 431-446, 2001.

LANGLEY LK, Overmier JB, KNOPMAN DS and ProD'Homme MS. Inhibition and habituation: Preserved mechanisms of attentional selection in aging and alzheimer's disease. Neuropsychology, 12: 353-366, 1998.

LARRUe V, CELsis P, BES A, and MARC-Vergnes J-P. The functional anatomy of attention in humans: Cerebral blood flow changes induced by reading, naming and the stroop effect. Journal of Cerebral Blood Flow and Metabolism, 14: 958-962, 1994.

Lough S, Kipps CM, Treise C, WATson P, Blair JR AND Hodges JR. Social reasoning, emotion and empathy in frontotemporal dementia. Neuropsychologia, 44: 950-958, 2006.

MATTIS S. Dementia rating scale. Secondary Titl. Windsor: NFER-Nelson, 1973.

McKhann G, Drachman D, Folstein M, Katzman R, Price D and Stadlan EM. Clinical diagnosis of alzheimer's disease: Report of the nincds-adrda work group under the auspices of departement of health and human services task force on alzheimer's disease. Neurology, 34: 939944, 1984.

Mendez MF, Chen AK, Shapira JS AND Miller BL. Acquired sociopathy and frontotemporal dementia. Dementia and Geriatric Cognitive Disorders, 20: 99-104, 2005.

Miller BL, Cummings Jl, Villanueva-Meyer J, Boone K, Mehringer CM, Lesser IM and Mena I. Frontal lobe degeneration: Clinical, neuropsychological, and spect characteristics. Neurology, 41: 1374-1382, 1991.

MiYake A, Friedman NP, Emerson MJ, WitzKi AH and Howerter A. The unity and diversity of executive functions and their contribution to complex "frontal lobe" tasks: A latent variable analysis. Cognitive Psychology, 41: 49-100, 2000.

Monsch AU, Bondi MW, SALMON DP, ButTers N, THAL LJ, HANSEN LA, Wiederholt WC, CAHN DA and KLAUBER MR. Clinical validity of the mattis dementia rating scale in detecting dementia of the alzheimer type. Archives of Neurology, 52: 899-504, 1995.

MORRIS RG. Recent developments in the neuropsychology of dementia. International Review of Psychiatry, 6: 85-107, 1994.

NeARy D, SNOWDEN JS, BOWEn DM, SIMS NR, MANn DMA, BENTON JS, NORTHEN B, YATES PO and DAVISON AN. Neuropsychological syndromes in presenile dementia due to cerebral atrophy. Journal of Neurology, 49: 163-174, 1986.

Neary D, Snowden JS, Gustafson L, Passant U, Stuss D, Black S, Freedman M, Kertesz A, Robert PH, Albert M, Boone K, Miller ML, Cummings J and Benson DF. Frontotemporal lobar degeneration. A consensus on clinical diagnostic criteria. Neurology, 51: 1546-1554, 1998.

NEILL WT. Inhibition and facilitation processes in selective attention. Journal of Experimental Psychology: Human Perception and Performance, 3: 444-450, 1977.

NIGG JT. On inhibition/disinhibition in developmental psychopathology: Views from cognitive and personality psychology and a working inhibition taxonomy. Psychological Bulletin, 126: 220-246, 2000.

Pachana NA, Brauer Boone K, Miller BL, Cummings JL and Berman N. Comparison of neuropsychological functioning in alzheimer's disease and frontotemporal dementia. Journal of the International Neuropsychological Society, 2: 505-510, 1996. 
Pulished in : Cortex (2007), 43, 866-874

Status : Postprint (Author's version)

Pardo JV, Pardo PJ, Janer KW and Raichle, ME. The anterior cingulate cortex mediates processing selection in the stroop attentional conflict paradigm. Proceedings of the National Academy of Sciences, USA, 87: 256-259, 1990.

PERRY RJ and HoDGES JR Differentiating frontal and temporal variant frontotemporal dementia from alzheimer's disease. Neurology, 54: 2277-2284, 2000.

POSNER MI and COHEN Y. Components of visual orienting. In Bouma H and Bouwhuis DG (Eds), Attention and performance X. London: Lawrence Erlbaum, 1984, pp. 531-556.

RABBiT P, LOWE C and SHILling V. Frontal tests and models of cognitive aging. European Journal of Cognitive Psychology, 13 : 5-28, 2001.

Salmon E, Garraux G, Delbeuck X, Collette F, Kalbe E, Zuendorf G, Perani D., FAZIO F. and HERHOLTZ K. Frontotemporal dementia is characterizes by ventromedial frontopolar metabolic impairment. Neuroimage, 20: 435-440, 2003.

Salmon E, Kerrouche N, Herholtz K, Perani D, Holthoff V, Beuthien-Baumanns B, Degueldre C, Lemaire C, LuXen A, Baron J-C, Collette F and Garraux G. Decomposition of metabolic brain clusters in the frontal variant of frontotemporal dementia. Neuroimage, 30: 871-878, 2006.

SAlmon E, SAdzot B, Maquet P, Degueldre C, Lemaire C, Rigo P, Comar D and Franck G. Differential diagnosis of alzheimer's disease with PET. Journal of Nuclear Medicine, 35: 391398, 1994.

SHILLING VM, CHETWYND A and RABBITT PMA. Individual inconsistency across measures of inhibition: an investigation of the construct validity of inhibition in older adults. Neuropsychologia, 40 : 605-619, 2002.

Sjogren M, Gustafson L, WiKKelso C and Wallin A. Frontotemporal dementia can be distinguished from alzheimer's disease and subcortical white matter dementia by an anteriortoposterior rcbf-pet ratio. Dementia and Geriatric Cognitive Disorders, 11: 275-285, 2000.

Slachevsky A, Villalpando JM, Sarazin M, Hahn-Barma V, Pillon B and Dubois B. Frontal assessment battery and differential diagnosis of frontotemporal dementia and alzheimer's disease. Archives of Neurology, 61: 1104-1107, 2004.

SPIELER DH, BALOTA DA and FAUST ME. Stroop performance in healthy younger and older adults and in individuals with dementia of the alzheimer's type. Journal of Experimental Psychology, 22: 461-479, 1996.

STARKSTEIN SE and ROBINSON RG. Mechanism of disinhibition after brain lesion. Journal of Nervous Mental Disorders, 185: 108-114, 1997.

STROOP JR. Studies of interference in serial verbal reactions. Journal of Experimental Psychology, 6: 643-661, 1935.

SULLIVAN MP, FAUST ME AND BALOTA DA. Identity negative priming in older adults and individuals with dementia of the alzheimer type. Neuropsychology, 9: 537-555, 1995.

TAYlor SF, KoRnblum S, LAUBer EJ, MinOShima S AND KoepPe RA. Isolation of specific interference processing in the stroop task: PET activation studies. Neuroimage, 6: 81-92, 1997.

TIPPER S. The negative priming effect: Inhibitory effects of ignored primes. Quarterly Journal of Experimental Psychology, 37A: 571-590, 1985.

Verhaeghen P and De MeErsman L. Aging and the stroop effect: A meta-analysis. Psychology and Aging, 13: 120-126, 1998.

Zimmermann P. and Fimm B. Tests d'évaluation de l'attention (TEA). Würselen: Psytest, 1994. 